\title{
The Development and Impact of Clinical Skills Hand- books in Undergraduate Medical Education
}

\author{
Nickan Motamedi ${ }^{1}$, Menachem Benzaquen ${ }^{1}$, Barbara Power ${ }^{1}$ \\ ${ }^{1}$ University of Ottawa, Faculty of Medicine
}

\section{ABSTRACT}

Introduction: Traditional teaching of clinical skills in medical school commonly entails didactic teaching followed by practice sessions with Standardized Patients (SPs) for particular skills, such as the cardiovascular exam. To address the need for briefer and more concise reference guides from standard textbooks and to consolidate skills expectations, the University of Ottawa developed clinical skills handbooks for students. The purpose of this study was to evaluate students' use of these handbooks in the pre-clinical and clinical years.

Methods: We distributed a survey to second, third, and fourth year medical students at the University of Ottawa from November 2016 to January 2017. The survey assessed how frequently students used the booklets and their opinions on the usefulness of the booklets as a learning tool.

Results: There were 121 respondents of 492 students eligible for the survey. Of the respondents, $96.7 \%$ claimed to have used the booklets, and $75 \%$ claimed it was their primary resource for physical exam skills education. The majority of pre-clinical students used the booklets when learning a physical exam $-65 \%$ almost always, and $97 \%$ at least sometmes. The majority of clinical students (also referred to as clerkship students) used the booklets when reviewing a physical exam - 25\% almost always, and $64 \%$ at least sometmes. Most students used the booklets when studying for OSCEs - $65 \%$ almost always, and $94 \%$ at least sometmes.

Conclusions: Students at the University of Ottawa found the clinical skills handbooks to be a valuable resource during their medical training and for the majority, it was their most commonly used reference. These findings support the need for further development and use of these resources.

RÉSUMÉ

Introduction: L'enseignement traditionnel des compétences cliniques à l'école de médecine implique généralement un enseignement didactique suivi de séances pratiques avec des patients standardisés (SP) pour des compétences particulières, telles que l'examen cardiovasculaire. Pour répondre au besoin de guides de référence plus concis à partir des manuels standards et pour consolider les attentes en matière de compétences, I'Université d'Ottawa a élaboré des manuels de compétences cliniques pour les étudiants. Le but de cette étude était d'évaluer l'utilisation de ces manuels par les étudiants dans les années pré-cliniques et cliniques. Méthodes: Nous avons distribué un sondage aux étudiants de deuxième, troisième et quatrième année en médecine à l'Université d'Ottawa de novembre 2016 à janvier 2017. Le sondage a évalué la fréquence d'utilisation des livrets et leurs opinions sur l'utilité des livrets comme outil d'apprentissage. .

Résultats: Il y avait 121 répondants de 492 étudiants admissibles à l'enquête. Parmi les répondants, 96,7\% ont déclaré avoir utilisé les brochures, et $75 \%$ ont affirmé que c'était leur ressource principale pour l'éducation aux compétences d'examen physique. La majorité des étudiants pré-cliniques utilisaient les livrets lorsqu'ils apprenaient un examen physique - $65 \%$ presque toujours, et $97 \%$ au moins parfois. La majorité des étudiants en clinique (également appelés étudiants stagiaires) ont utilisé les brochures pour la préparation pour l'examen - $25 \%$ presque toujours, et $64 \%$ au moins parfois. La plupart des étudiants ont utilisé les brochures lorsqu'ils étudiaient pour les OSCE - $65 \%$ presque toujours, et $94 \%$ au moins parfois.

Conclusions: Les étudiants de l'Université d'Ottawa ont trouvé que les guides sur les compétences cliniques étaient une ressource précieuse durant leur formation médicale et que, pour la majorité d'entre eux, c'était leur référence la plus couramment utilisée. Ces résultats appuient la nécessité de poursuivre le développement et l'utilisation de ces ressources.

Keywords: Handbook; Booklet 
$\mathbf{T}$ he acquisition of clinical skills is a core component of medical education and a basic element of physician skills that is important throughout a physician's career (1). A common teaching method for clinical skills involves the use of Standardized Patients (SPs) - individuals who have been trained to simulate real patient interactions, allowing students to practice clinical skills in a standardized method and under the supervision of a tutor. This approach is recommended by the American Association of Medical Colleges over didactic methods (1). This method is useful as it allows students to receive feedback from both the SPs and a trained clinician, allows for translation of skills from knowledge to application, and can be used for testing purposes (2-5). However, because these sessions tend to be limited to a specific component of the physical exam and may only focus on a particular anatomical system for a few sessions, the value of this approach as a long-term consolidation of physical examination skills is unclear.

Typically, the approach to teaching physical exam skills is to focus on the "core" aspects of the physical exam in order for the learner to develop a strong foundation $(6,7)$. Less common or applicable components of the exam are also taught, but emphasized to only be applied if clinical context is appropriate $(7,8)$. For example, auscultation of the lung fields in a respiratory exam would be taught as a "core" exam skill, whereas eliciting egophony would be context-dependent. This approach is asserted to have better teaching value and long-term consolidation of skills as it is easier to learn, remember, and is more clinically useful since the focus is on the acquisition of basic skills (7).

Despite the fact that physical examination skills are one of the cornerstones of medical education, the literature is limited in describing central resources students may access to review physical exam skills during their clinical years in medical school and/or in residency training. Textbooks such as "Bates Guide to Physical Exam and History-taking" are used as a popular resource for reviewing specific items and for reviewing detailed examination approaches. However, lengthy texts are felt to be cumbersome and overly-inclusive for students (7). To address the need for a more simplified approach, the University of Ottawa Faculty of Medicine developed clinical skills handbooks to facilitate learning at the pre-clinical level, and to serve as a long-term simplified and practical reference guide for clinical years. To date, there is no published literature that describe the utility of clinical skills handbooks as a teaching tool for the physical examination in undergraduate medical education, despite the curriculum at the University of Ottawa Undergraduate Medicine employing this tool for years. The purpose of this study was to evaluate University of Ottawa medical students' perceived utility of the clinical skills handbooks after 2-3 years of use.

\section{METHODS}

\section{Handbooks}

University of Ottawa Undergraduate Medicine students were surveyed on their opinion of the usefulness of the Clinical Skills Examination handbooks (also referred to as "booklets"). These booklets were developed by students and residents in collaboration with content experts in the Faculty of Medicine as a resource to help medical students learn physical examination skills. They included a history-taking booklet and four physical examination handbooks on: Musculoskeletal Examination; Cardiovascular, Respiratory, and Abdominal Examinations; Head and Neck Examinations; and Neurological Examination. Students had free online access to the handbooks as supplemental material to lectures introducing the physical exams, textbooks, and small group skills teachings sessions for the various components of the physical exam. The handbooks were also emailed to students by the faculty 1-5 weeks in advance of the skills sessions. The handbooks outline the components of a general physical exam or history and the relevant interpretation of findings (e.g. significance of an S3 on cardiac auscultation). There are also adjacent boxes with clinical pearls (e.g. differential diagnosis for a Relative Afferent Pupillary Defect), and diagrams to illustrate anatomy and landmarks (e.g. outlining the landmarks of Traube's space or the Right Middle Lung Lobe). The handbooks also contain sections outlining common focused physical exams such as an approach to volume status assessment.

\section{Survey}

An electronic survey was created by the authors (see Appendix A). It included questions about demographics of the students surveyed; setting in which the students used the handbooks as a reference; the impact the booklets made on students' learning of the physical exam and of the general clinical skills curriculum; the usefulness of additional features of the handbooks (diagrams, clinical pearls); as well as students' use of other resources (Bates Guide to Physical Examination and History-taking, Toronto Notes, and YouTube Videos). There were three comment sections - one for students to describe other resources 
they use for the learning of clinical skills, one for suggestions on improvement of the booklets, and a general comment section. As part of the surveys, Likert scales were used to assess students' self-perceived frequency and usefulness of booklet use (e.g. "Almost Always", "Often", "Sometmes", "Rarely", "Never" for frequency) rather than attempting to numerically quantify these metrics, as it was felt that there was a wide-spectrum of frequency and thoroughness of booklet use. The Likert scales provided the advantage of allowing students to judge their frequency and thoroughness of booklet use into an interpretable response that was comparable to their peers and more readily interpreted by the larger academic community.

The survey was circulated by email to second, third, and fourthyear students via the class presidents. The first-year class was excluded as they had only been taught history-taking and the musculoskeletal exam at the tme of the survey. The survey was a Google Form that was completed anonymously. Surveys were gathered from November 29, 2016 through January 27, 2017 for a total of 60 days.

\section{Analysis}

Data from the survey was compiled into two subgroups: second year students only (pre-clinical respondents), and third and fourth-year students only (clinical clerkship respondents). These subgroups were only used to compare responses to two specific questions: medical students' perceived utility of the handbooks when learning an examination (pre-clinical group), and perceived utility when reviewing an examination for clinical purposes (clinical group). Results from all other questions were relevant to all respondents and were analyzed without subgroups. No special analyses were performed beyond tabulation of responses.

\section{RESULTS}

There were 492 students across the three classes of students who were asked to complete the survey. Student response rate was $24.5 \%$ (121/492). Of the respondents, $26.4 \%$ were from the 2nd year class (pre-clinical subgroup $n=32$ ); $56.2 \%$ were from the 3 rd year class and $17.4 \%$ were from the 4 th year class (clinical subgroup $\mathrm{n}=89$ ). Of the respondents, $54.5 \%$ were male and $45.5 \%$ female.

As shown in Figure 1, the majority of medical students surveyed used the booklets when practicing their physical exams (41\% almost always, $87 \%$ at least sometmes), and when study- ing for Objective Structured Clinical Examinations (OSCEs) $65 \%$ almost always, $94 \%$ at least sometmes). In the pre-clinical subgroup, a majority used the booklets when learning a physical exam (65\% almost always, $97 \%$ at least sometmes). In the clinical subgroup (i.e. clinical clerks), there was a smaller number that used the booklets when reviewing an exam for clinical purposes (25\% almost always, $64 \%$ at least sometmes). 117 (96.7\%) students who completed the survey claimed to have used the handbooks at some point during their training.

Figure 2 demonstrates the impact the booklets had on the students' learning of clinical skills. The majority used the booklets as their primary resource for clinical skills ( $75 \%$ agree or strongly agree, $11 \%$ disagree or strongly disagree), felt the booklets improved their clinical skills $(88 \%$ agree or strongly agree, $3 \%$ disagree or strongly disagree), and felt they needed the booklets to achieve success in the clinical skills portion of the curriculum ( $75 \%$ agree or strongly agree, $10 \%$ disagree or strongly disagree).

The most popular booklet used by the students was the Cardiovascular, Respiratory, and Abdominal Exam booklet with 95.9\% $(116 / 121)$ having used it, as shown in Figure 3. Use of other booklets were as follows: The Musculoskeletal Exam booklet - 95\% (115/121); Neurological Exam booklet - 71.9\% (87/121), History-taking booklet - 66.9\% (81/121), and Head and Neck Exam booklet $-62 \%$ (75/121). There were 4 respondents who indicated having not used any booklets.

Figure $\mathbf{4}$ shows the respondents' subjective frequency of use of three other commonly used alternative education resources for physical examination skills. Listed in order of most frequently used, respondents reported: YouTube videos (14.9\% almost always, $81.8 \%$ at least sometmes); Bates' Guide to Physical Examination and History-taking ( $2.5 \%$ almost always, $47 \%$ at least sometmes) followed by Toronto Notes (3.3\% almost always, $37.2 \%$ at least sometmes).

The most common suggestions from respondents regarding improving the handbooks were to improve the diagrams and incorporate videos or video links detailing certain physical examination techniques further.

\section{DISCUSSION}

This study demonstrated that nearly every medical student (96.7\%) who responded to the survey used the booklets at 
Pre-clinical subgroup: How often do you use the Physical Exam booklets when learning a physical exam?

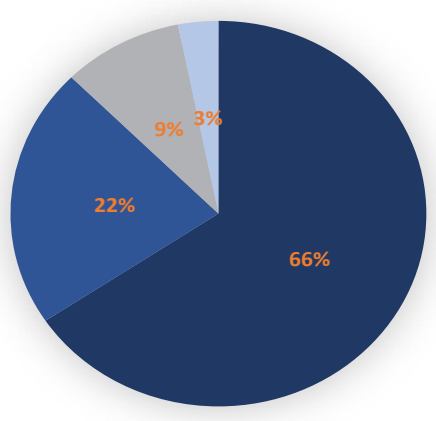

How often do you use the Physical Exam booklets when studying for OSCEs?

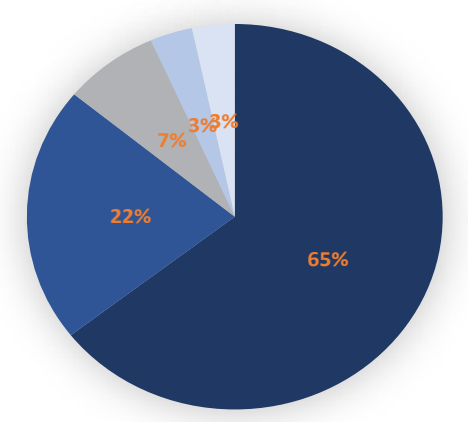

How often do you use the Physical Exam booklets when practicing a physical exam?

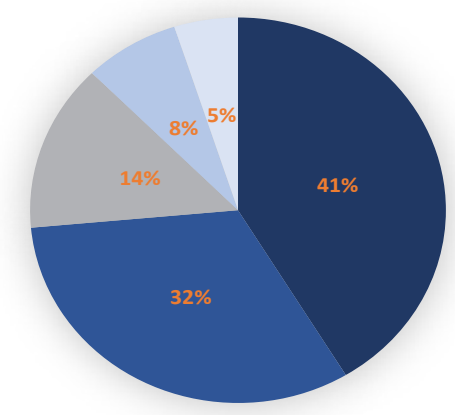

Clinical subgroup: How often do you use the Physical Exam booklets when reviewing an exam for clinical purposes?

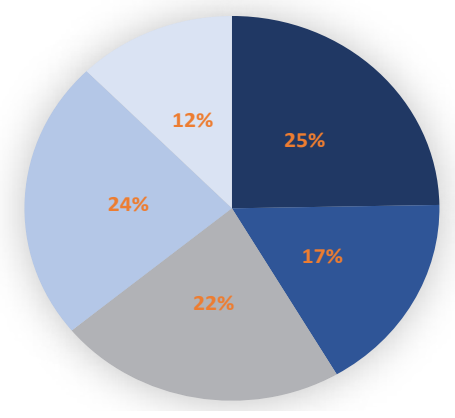

- Almost always

- Often

- Sometimes

$\square$ Rarely

Never

Figure 1. Responses to questions regarding setting and use of the Physical Examination handbooks.
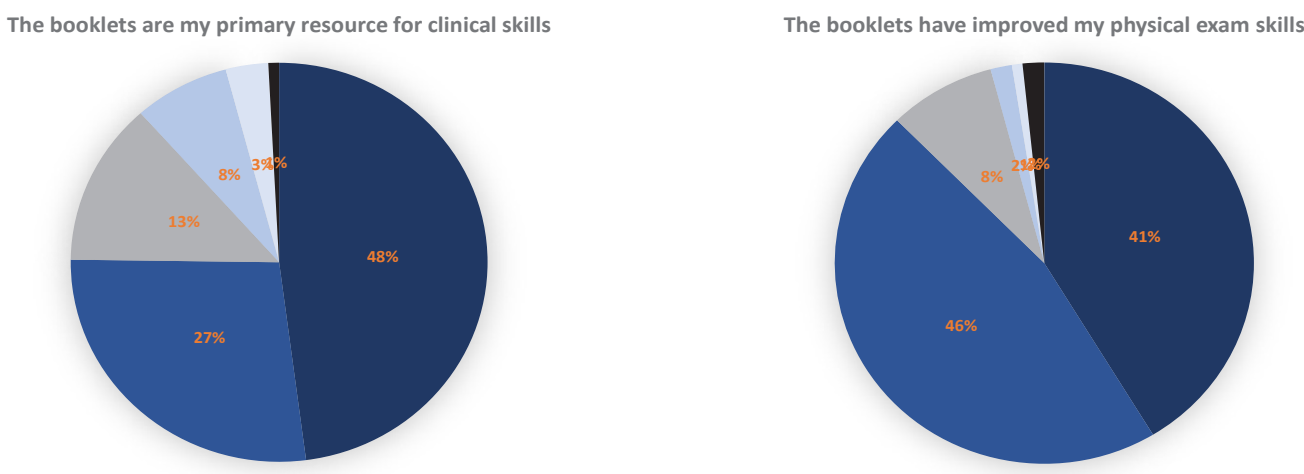

I need the booklets to achieve success in the clinical skills

portion of the curriculum

\begin{tabular}{|l|}
\hline - Strongly Agree \\
- Agree \\
— Unsure \\
Disagree \\
Strongly Disagree \\
N/A \\
\hline
\end{tabular}

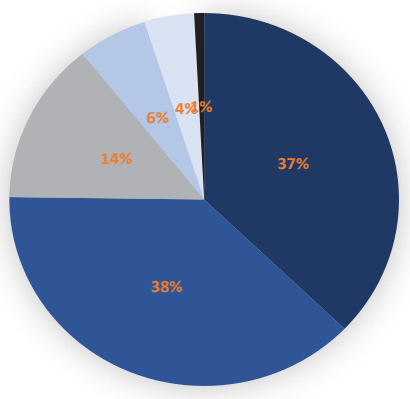

Figure 2. Responses to questions regarding subjective impact of Physical Examination handbooks for students. 
some point during their training. Of the four students who did not, three added in the comment section that a language barrier was the reason. The University of Ottawa has the only bilingual Undergraduate Medicine program in Canada with both a French and English stream in each matriculating class. Since this survey has been completed the booklets have all been translated into French, which was a previous limitation.

The initial purpose for the development of the clinical skills booklets was to assist pre-clerkship students in their learning of physical exam skills either when they were practicing in a group, preparing for an OSCE, or learning on their own. This survey supports that the booklets serve this purpose, as a majority of students used the booklets when learning physical exam skills (65\% almost always, $97 \%$ at least sometmes).

The second purpose of the booklets was to serve as a reference during clinical (clerkship) years. While not as commonly used for this purpose compared to as a learning resource for the introduction to a physical exam, a majority of participants in their clinical rotations still commonly used the handbooks for reference. Among the clinical subgroup, 25\% almost always used the booklets, and $64 \%$ at least sometmes. This supports that the booklets also have a role as a reference during clinical training.

The results also support the concept that the booklets are an important component in the training of clinical skills for medical students. $65 \%$ of respondents reported almost always using the handbooks for OSCEs preparation, $75 \%$ used the handbooks as their primary resource for physical exam skill education, $88 \%$ stated that that handbooks have improved their clinical skills, and $80 \%$ stated that the handbooks have helped them succeed in the clinical skills curriculum. These results demonstrate that there is strong consensus among students that the handbooks are a valuable resource in medical school.

The results highlighted that the combined Cardiac, Respiratory, and Abdominal exam booklet and the Musculoskeletal exam booklet are the most frequently used booklets with greater than $95 \%$ of respondents using them. To explain this trend, the authors hypothesize that early in the curriculum, medical students are more likely to follow faculty-designated resources, as they have not yet explored other options or discovered their own personalized resources and tools for studying. With experience, students may discover strategies and resources that are more suited to their own learning and depend less on these handbooks. The aforementioned two booklets cover nearly all of the first year clinical skills curriculum and are therefore most popular, in contrast to the Head and Neck and Neurological examinations which are only introduced in the second-year curriculum and are less frequently used. Nevertheless, the data suggests that all the booklets are used by most students, as demonstrated in Figure 3.

Our results demonstrate that YouTube videos are the most popular alternative resource for students to use, with $82 \%$ using them at least sometmes, in contrast to $46 \%$ and $37 \%$ for Bates Guide to Physical Examination and History-taking and Toronto Notes, respectively (Figure 4). Two of the most common suggestions for improving the handbooks involved incorporating videos in some capacity, and improving the diagrams. This suggests that visual aids are valued by students, in comparison to other text-based tools.

Our survey received a moderate response rate at $24.6 \%$. There was a bias toward the $3 \mathrm{rd}$ year class, representing $56.2 \%$ of respondents, compared to $26.4 \%$ and $17.4 \%$ from the 2 nd and 4 th year classes, respectively. A reason for this bias may be due to the fact that the authors of the study are from the 3rd year class and this might have influenced more students from their class to respond. Despite the different response rates, the method of circulating the survey was uniform. The sampling discrepancy affected the result for the number of students reporting having used the Head and Neck Examination booklet, as this booklet was not created until the $4^{\text {th }}$ year students were into their first clinical year. This may also explain why it was the least popular booklet (Figure 3).

Limitations of this study are predominantly related to the inherent nature of survey research and response biases. Students were familiar with the authors of the study which may have prompted selection bias, as well as the general favorability towards the booklets. While problematic, these biases were somewhat mitigated as the survey was described to students as a faculty initiative to gather feedback, rather than a research tool for publication by the authors who were classmates. This study also had difficulty defining and quantifying broad terms such as "usefulness" of booklets, as attempts to objectively define and quantify this term was deemed unreliable for study purposes. For example, the authors understood that two different students may use the booklets at differing frequency, but this may 


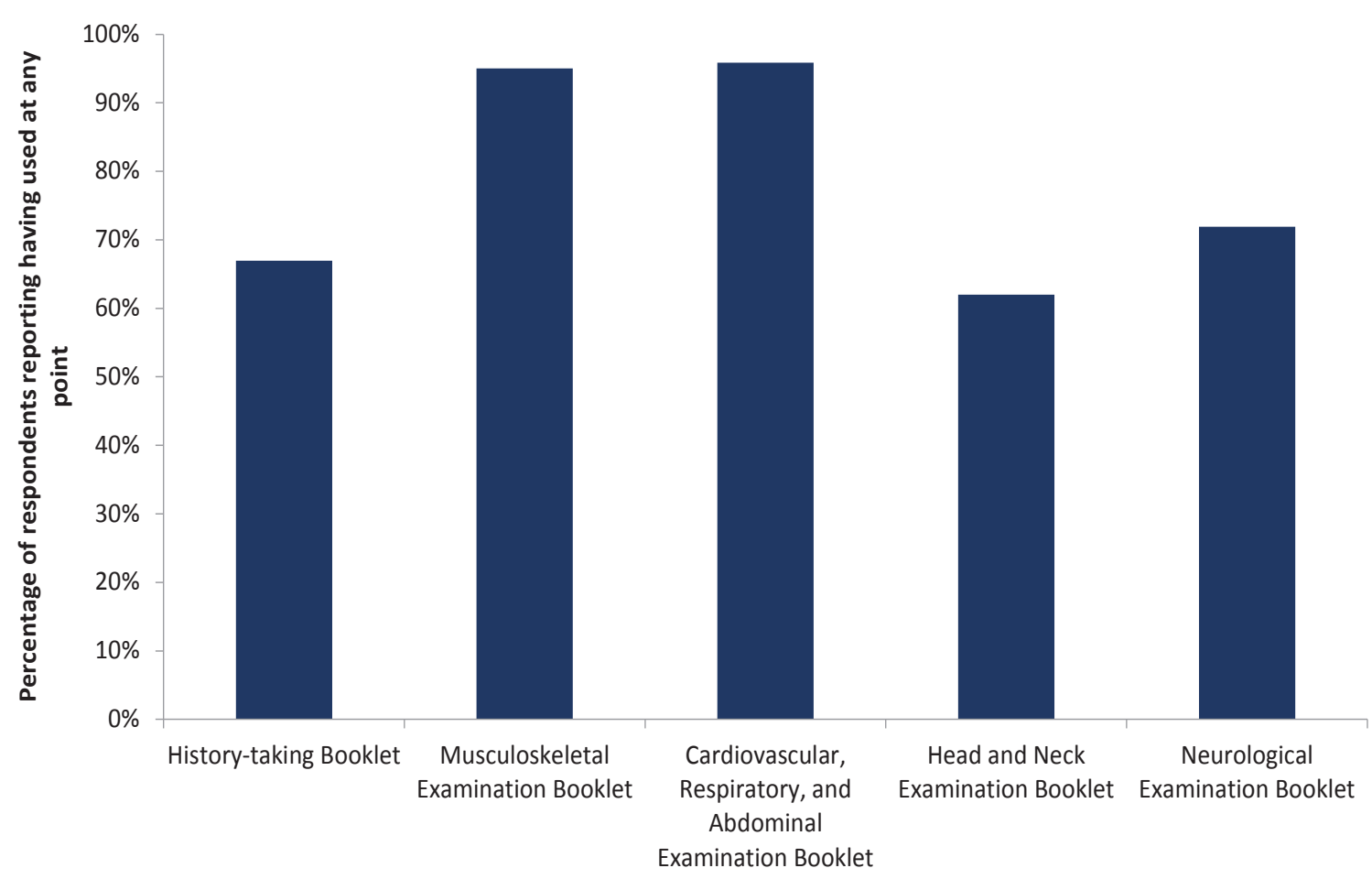

Figure 3. Percentage of respondents reporting having used each of the clinical skills handbooks.

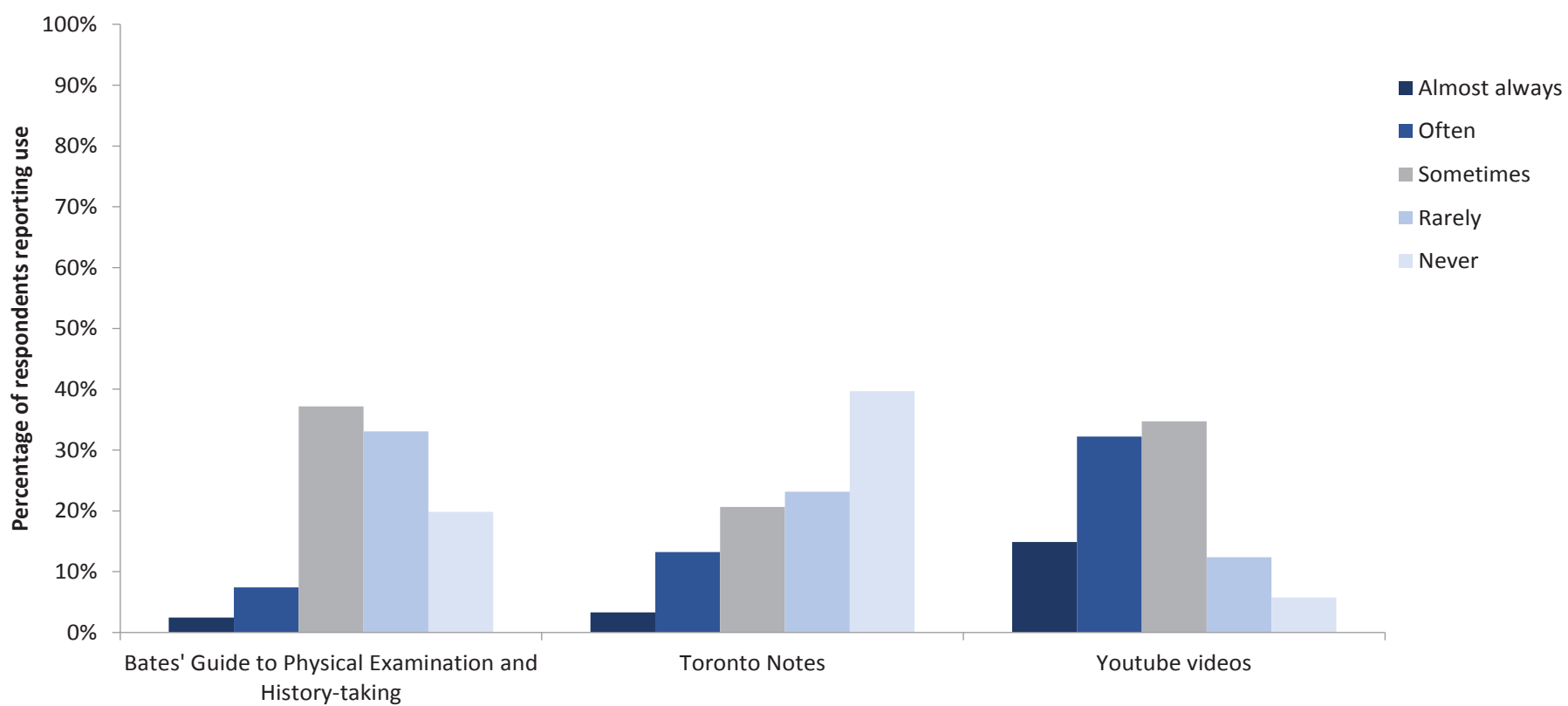

Figure 4. The respondent cohort's subjective frequency of use of each of the three common alternative resources posed in the survey: Bates' Guide to Physical Examination and History-taking, Toronto Notes, and Youtube videos. 
simply be explained by one student studying more than the other, and subsequently using the handbooks more frequently out of work ethic rather than perceived usefulness of the booklet. As such, questions about respondents' subjective opinions on usefulness, comparisons with other tools, and respondents' self-attributed success related to use of the booklets were employed to better define the helpfulness of the booklets. Despite these limitations, the paucity of scholarly literature in describing this form of tool in medical education mandates that this study be a starting point for future evaluation and employment of such tools.

\section{CONCLUSION}

The University of Ottawa Undergraduate Medicine content experts, in collaboration with medical students and residents, developed clinical skills booklets to facilitate the learning of physical examination skills at the pre-clinical level and to be used as a resource and reference during clinical years. While there are described methods of physical exam education in pre-clinical training, there is limited evidence for strategies in clinical years. This survey of second, third, and fourth-year medical students demonstrated that the handbooks are an important tool and resource of medical undergraduate education in regards to clinical skills development. The majority of students surveyed use the handbooks on a regular basis and found the handbooks to be a popular and valuable resource for students across pre-clinical and clinical years of medical training. These findings suggest the need for further development of these forms of resources as learning tools to enhance the teaching of clinical skills. Future research may be oriented at identifying which components of the booklets are most useful for students and how the students perceive the usefulness of these booklets compared to other educational resources. Further investigations into their efficacy could influence the decision of medical educators at other centers to adopt these teaching tools as a reference.

\section{ACKNOWLEDGEMENTS}

Acknowledgements to the previous editors who have worked on these handbooks: Dr. Melissa Vivey, Dr. Brodie Ramin, Dr. Ken Kontio, Yingwei Liu, and Michael Colapinto.

\section{REFERENCES}

1. Recommendations For Clinical Skills Curricula for Undergraduate Medical Education [Internet]. Washington DC: AAMC Task Force on the Clinical Skills Education of Medical Students; 2008 [Cited 2017 Sept 18]. Available from: https://www.aamc.org/download/130608/data/clinicalskills_oct09. qxd.pdf.pdf
2. Miller GE. The assessment of clinical skills/competence/performance. Acad med. 1990;65(9):S63-7.

3. Barrows HS. An overview of the uses of standardized patients for teaching and evaluating clinical skills. AAMC. Acad Med. 1993;68(6):443-51.

4. Epstein RM. Assessment in medical education. $\mathrm{N}$ Engl J Med 2007;(356):387-396.

5. Williams RG. Have standardized patient examinations stood the test of tme and experience? Teach Learn Med. 2004;16(2):215-222.

6. Haring CM, van der Meer JW, Postma CT. A core physical examination in internal medicine: What should students do and how about their supervisors? Med teach. 2013;35(9):e1472-e1477.

7. Gowda D, Blatt B, Fink MJ, Kosowicz LY, Baecker A, Silvestri RC. A core physical exam for medical students: results of a national survey. Acad Med. 2014;89(3):436-442.

8. Uchida T, Farnan JM, Schwartz JE, Heiman HL. Teaching the physical examination: a longitudinal strategy for tomorrow's physicians. Acad Med. 2014;89(3):373-375 